\title{
Voice Alteration, CTCAE
}

National Cancer Institute

\section{Source}

National Cancer Institute. Voice Alteration, CT CAE. NCI Thesaurus. Code C143941.

A disorder characterized by a change in the sound and/or speed of the voice. 